\title{
Modelling \& Designing Land Record Information System Using Unified Modelling Language
}

\author{
Kanwalvir Singh Dhindsa \\ CSE \& IT Department, \\ B.B.S.B.Engg.College, \\ Fatehgarh Sahib,Punjab,India \\ kdhindsa@gmail.com
}

\author{
Himanshu Aggarwal \\ Department of Computer Engg., \\ Punjabi University, \\ Patiala, Punjab,India \\ himanshu@pbi.ac.in
}

\begin{abstract}
Automation of Land Records is one of the most important initiatives undertaken by the revenue department to facilitate the landowners of the state of Punjab. A number of such initiatives have been taken in different States of the country. Recently, there has been a growing tendency to adopt UML (Unified Modeling Language) for different modeling needs and domains, and is widely used for designing and modelling Information systems. UML diagramming practices have been applied for designing and modeling the land record information system so as to improve technical accuracy and understanding in requirements related with this information system. We have applied a subset of UML diagrams for modeling the land record information system. The case study of Punjab state has been taken up for modelling the current scenario of land record information system in the state. Unified Modeling Language (UML) has been used as the specification technique. This paper proposes a refined software development process combined with modeled process of UML and presents the comparison study of the various tools used with UML.
\end{abstract}

Keywords - Information system, Unified Modeling Language (UML), software modelling, software development process, UML tools.

\section{INTRODUCTION}

Computerization of Land Records is one of the most important initiatives undertaken by the Revenue Department to facilitate the landowners of the State. A number of such initiatives have been taken in different States of India. The paper proposes a UML based approach, where nonfunctional requirements are defined as reusable aspects to design and analysis. UML offers vocabulary and rules for communication and focus on conceptual and physical representations of a system. UML uses an object oriented approach to model systems which unifies data and functions (methods) into software components called objects. Various diagrams are used to show objects and their relationships as well as objects and their responsibilities (behaviors). UML is Standard for objectoriented modeling notations endorsed by the Object Management Group (OMG), an industrial consortium on object technologies. UML has become a standard after combining and taking advantage of a number of object oriented design methodologies (Kobryn, 1999) and is currently posed as a modeling language instead of a design process.

\section{A. Process of Data Digitisation}

The automation of the projects related with information systems is underway in many Govt. sectors. With the use of the funds, 153 Fard kendras will be established in the Tehsils of the State to provide certified copies of the Revenue Records to the general public. Some farad centres have been already opened in few tehsils and sub-tehsils, for to be used by public. The land records (Jamabandi etc.), generally are updated after every 5 years. The legacy land records to be digitized are: Jamabandi, Mutation, Roznamcha Waqiati, Khasra Girdawari and Field Book. Lack of faith and undefined procedures regarding services being provided to the citizens. This implementation of changing the paper record into digital records will lead to facilitation of the farmers, maintaining better transparency of the revenue records, lead to drastic reduction of fraudulent practices, level of corruption and procedural hassles relating to the management of the land records, will lead to reduction in time delay and will also work as a faith building measure, providing service to citizens.

\section{Unified Modelling LANGUAGE}

UML (Unified Modelling Language) is a complete language for capturing knowledge(semantics) about a subject and expressing knowledge(syntax) regarding the subject for the purpose of communication. It applies to modeling and systems. Modeling involves a focus on understanding a subject (system) and being able to communicate in this knowledge. It is the result of unifying the information systems and technology industry's best engineering practices (principals, techniques, methods and tools). It is used for both database and software modeling. UML attempts to combine the best of the best from: Data Modeling concepts (Entity Relationship Diagrams), Business Modeling (work flow), Object Modeling and Component Modeling. UML is defined as: "UML is a graphical language for visualizing, specifying, constructing, and documenting the artifacts of a software intensive system" [Booch]. Software architecture is an area of software engineering directed at developing large, complex applications in a manner that reduces development costs, increases the quality and facilitates evolution[8]. A central and critical problem software architects face is 
how to efficiently design and analyze software architecture to meet non- functional requirements. UML offers vocabulary and rules for communication and focus on conceptual and physical representations ofa system.

The various structural things in UML are Class, Interface, Collaboration, Use-case, behavioral things comprise of Interaction, State machine, Grouping things comprise of packages and notes.

a) Things: important modeling concepts.

b) Relationships: tying individual things (i.e., their concepts).

c) Diagrams: grouping interrelated collections of things and relationships.

The artifacts included in standard UML consist of: Use case diagram, Class diagram, Collaboration diagram, Sequence diagram, State diagram, Activity diagram, Component diagram and Deployment diagram (OMG, 1999).There are different ways of using UML in terms of design methodologies to accomplish different project objectives.

\section{SYSTEM ANALYSIS \& DESIGN}

Unified Modeling Language (UML) is used as a specification technique for the system analysis and design process involved in the software development life cycle.

\section{A. Modelling \& Designing Using UML}

\section{1) Case Scenario : Land Record Information System}

UML is built upon the MOFTM metamodel for OO modeling. A modeling method comprises a language and also a procedure for using the language to construct models, which in this case is Unified Modeling Language(UML). Modeling is the only way to visualize one's design and check it against requirements before developers starts to code. The land record information system is modeled using use-case, sequence, class, and component diagrams offered by the Unified Modeling Language.

a) Use-Case Diagram: Use case diagrams describe what a system does from the standpoint of an external observer [17]. Use Case Diagrams describe the functionality of a system and users of the system. And contain the following elements:

- Actors, which represent users of a system, including human users and other systems.

- Use Cases, which represent functionality or services provided by a system to users.

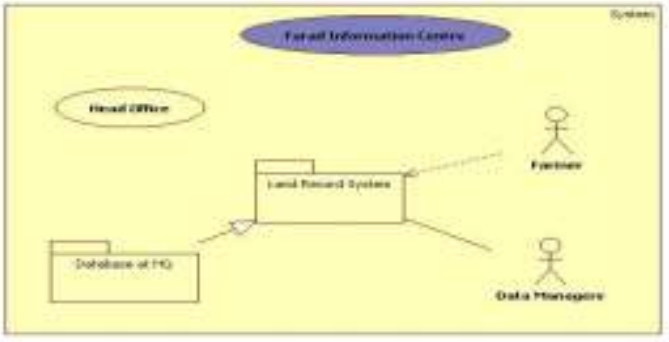

$\{*$ as modeled in StarUML \}

b) Class Diagrams \& Object Diagrams: Being the most important entity in modeling object-oriented software systems, it is used to depict the classes and the static relationships among them [3]. Class Diagrams describe the static structure of a system, or how it is structured rather than how it behaves. These diagrams contain the following elements:

- Classes, which represent entities with common characteristics or features. These features include attributes, operations and associations.

- Associations, which represent relationships that relate two or more other classes where the relationships have common characteristics or features.

c) Object Diagrams: describe the static structure of a system at a particular time. Whereas a class model describes all possible situations, an object model describes a particular situation. Object diagrams contain the following elements:

- Objects, which represent particular entities. These are instances of classes.

- Links, which represent particular relationships between objects. These are instances of associations.

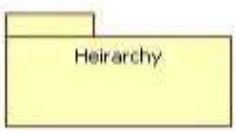

Database

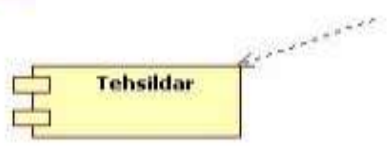

$\{*$ as modeled in StarUML \}

d) Collaboration Diagrams \& Component Diagrams: Component diagram is one of UML's architectural diagrams used to effectively describe complex architectures as a hierarchy of components (subsystems) communicating through defined interfaces [6]. Collaboration Diagrams describe interactions among classes and associations. These interactions are modeled as exchanges of messages between classes through their associations. Collaboration diagrams are a type of interaction diagram. Collaboration diagrams contain the following elements:

i) Class roles, which represent roles that objects 
may play within the interaction.

ii) Association roles, which represent roles that links may play within the interaction.

iii) Message flows, which represent messages sent between objects via links. Links transport or implement the delivery of the message.

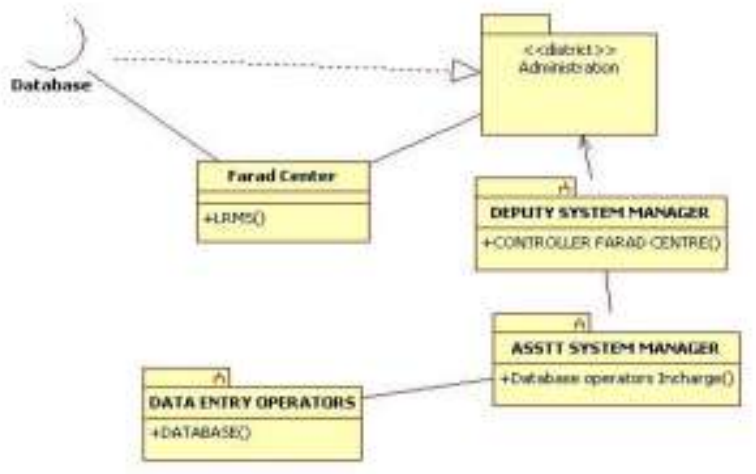

\{*as modeled in StarUML

e) Deployment Diagrams : Deployment diagrams describe the configuration of processing resource elements and the mapping of software implementation components onto them. These diagrams contain components and nodes, which represent processing or computational resources, including computers, printers, etc. Each cube icon is known as a node representing a physical system. All the system requirements are shown in the architecture which is used for the land record information system. All the modules of the information system have been developed using Visual Basic with SqlServer at the backend. The web components are hosted on Apache web server and use Java Servlets. The modeled components* are shown in the deployment diagram.

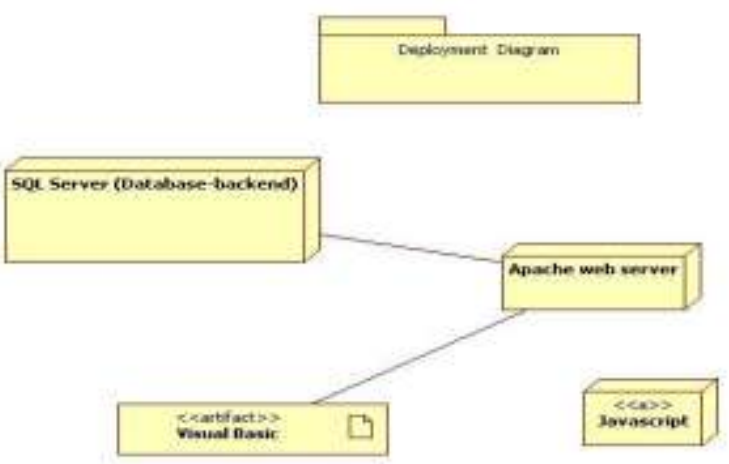

$\{*$ as modeled in StarUML \}

IV. MODELLING TOOLS USED IN UML

The various types of tools used for modelling in Unified
Modeling Language(UML) are:

a) Modeling Tools : Rational Rose, ArgoUML, Together,

UMbrello

b) Drawing Tools : Visio, Dia

c) Metamodels: Eclipse UML2, NSUML, OMF

d) Renderers: Graphviz, UMLDoc

e) IDEs: Visual Studio 2005, XCode 2,

Rational XDE

\section{A. Comparison of UML Tools}

The Unified Modelling Language(UML) tools used for modeling the design of various information systems are compared by taking some vital parameters which distinguish each one of them; giving fairly the advantage of one tool over the other.

TABLE I. COMPARISON OF UML TOOLS

\begin{tabular}{|c|c|c|c|c|}
\hline Tools & Strength/Stability & Cost & $\begin{array}{c}\text { Additional } \\
\text { Features }\end{array}$ & $\begin{array}{c}\text { Current } \\
\text { Status }\end{array}$ \\
\hline $\begin{array}{l}\text { Rational } \\
\text { Rose }\end{array}$ & $\begin{array}{l}\text { Full-strength } \\
\text { modeling suite }\end{array}$ & $\begin{array}{l}\text { expensi } \\
\text { ve }\end{array}$ & $\begin{array}{l}\text { Office for UML, } \\
\text { add-ons, plug- } \\
\text { ins, scripting } \\
\text { interface, } \\
\text { plug-in to MS } \\
\text { Visual Studio } \\
\text { and Eclipse }\end{array}$ & $\begin{array}{l}\text { Re- } \\
\text { developed } \\
\text { Rational } \\
\text { XDE }\end{array}$ \\
\hline Together & $\begin{array}{l}\text { Supports most } \\
\text { UML diagrams }\end{array}$ & $\begin{array}{l}\text { Mid- } \\
\text { range } \\
\text { cost }\end{array}$ & $\begin{array}{l}\text { Can reverse } \\
\text { engineer with } \\
\text { C++,Java } \\
\text { - Generate } \\
\text { source code } \\
\text { for } \\
\text { C++, Java }\end{array}$ & $\begin{array}{l}\text { Exports to } \\
\text { PNG }\end{array}$ \\
\hline ArgoUML & $\begin{array}{l}\text { Open source } \\
\text { UML modeling } \\
\text { application } \\
\text { written in Java }\end{array}$ & $\begin{array}{l}\text { Free to } \\
\text { downlo } \\
\text { ad }\end{array}$ & $\begin{array}{l}\text { Supports most } \\
\text { diagram types, } \\
\text { reverse } \\
\text { engineering } \\
\text { and code } \\
\text { generation for } \\
\text { Java }\end{array}$ & $\begin{array}{l}\text { Forked } \\
\text { into } \\
\text { commercial } \\
\text { product } \\
\text { Poseidon }\end{array}$ \\
\hline Umbrello & $\begin{array}{l}\text { Open source } \\
\text { modeling } \\
\text { application for } \\
\text { KDE, written in } \\
\mathrm{C}++\end{array}$ & $\begin{array}{l}\text { Free to } \\
\text { downlo } \\
\text { ad }\end{array}$ & $\begin{array}{l}\text { Supports data } \\
\text { modeling for } \\
\text { SQL, reverse } \\
\text { engineering } \\
\text { and code } \\
\text { generation }\end{array}$ & $\begin{array}{l}\text { Under } \\
\text { developmen } \\
\mathrm{t}\end{array}$ \\
\hline MS Visio & $\begin{array}{l}\text { Fairly compliant } \\
\text { with UML } \\
\text { metamodel }\end{array}$ & $\begin{array}{l}\text { Not } \\
\text { interop } \\
\text { erable }\end{array}$ & $\begin{array}{l}\text { used for creating } \\
\text { 2D schematics } \\
\text { and diagrams }\end{array}$ & \\
\hline
\end{tabular}




\begin{tabular}{|c|c|c|c|c|}
\hline Dia & $\begin{array}{l}\text { Open source } \\
\text { graphics drawing } \\
\text { Program form } \\
\text { GNOME }\end{array}$ & Free & $\begin{array}{l}\text { Supports the } \\
\text { creation of } \\
\text { some } \\
\text { UML diagram } \\
\text { types }\end{array}$ & $\begin{array}{l}\text { Used } \\
\text { frequently } \\
\text { by open } \\
\text { Source } \\
\text { develop } \\
\text { ers }\end{array}$ \\
\hline $\begin{array}{l}\text { Graphviz } \\
\text { and } \\
\text { UMLDoc }\end{array}$ & $\begin{array}{l}\text { AT\&T Graphviz } \\
\text { graph } \\
\text { specification } \\
\text { input, generates } \\
\text { PNG, PDF } \\
\text { layouts of graphs } \\
\text { UMLDoc - } \\
\text { parses Java } \\
\text { comments to } \\
\text { produce } \\
\text { diagrams }\end{array}$ & $\begin{array}{l}\text { mid- } \\
\text { range }\end{array}$ & $\begin{array}{l}\text { generates PNG, } \\
\text { PDF layouts of } \\
\text { graphs } \\
\text { Actually uses } \\
\text { graphviz to } \\
\text { create diagrams }\end{array}$ & \\
\hline $\begin{array}{l}\text { MS-Visual } \\
\text { Studio }\end{array}$ & $\begin{array}{l}\text { Supports UML- } \\
\text { like diagrams } \\
\text { for .NET } \\
\text { languages (i.e., } \\
\text { C\#) }\end{array}$ & $\begin{array}{l}\text { New } \\
\text { part in } \\
\text { VS } \\
2005\end{array}$ & $\begin{array}{l}\text { Provides support } \\
\text { for roundtrip } \\
\text { engineering, }\end{array}$ & $\begin{array}{l}\text { New part in } \\
\text { VS } 2005\end{array}$ \\
\hline XCode2 & $\begin{array}{l}\text { Claims support } \\
\text { for } \mathrm{C}, \mathrm{C}++ \text {, } \\
\text { and Java }\end{array}$ & & $\begin{array}{l}\text { Provides UML- } \\
\text { likeclass } \\
\text { diagrams for } \\
\text { Objective-C, } \\
\text { Can be used } \\
\text { for roundtrip } \\
\text { engineering }\end{array}$ & $\begin{array}{l}\text { Provides } \\
\text { UML-like } \\
\text { class } \\
\text { diagrams } \\
\text { for } \\
\text { Objective-C }\end{array}$ \\
\hline $\begin{array}{l}\text { Rational } \\
\text { XDE }\end{array}$ & $\begin{array}{l}\text { Visual modeling } \\
\text { suite for } \\
\text { UML }\end{array}$ & Costly & $\begin{array}{l}\text { Plugs in to } \\
\text { many different } \\
\text { IDE's (Visual } \\
\text { Studio .NET, } \\
\text { Eclipse, IBM } \\
\text { WebSphere), } \\
\text { Supports } \\
\text { roundtrip } \\
\text { engineering }\end{array}$ & $\begin{array}{l}\text { Provides } \\
\text { Rational } \\
\text { Rose }\end{array}$ \\
\hline
\end{tabular}

\section{UML IN INFORMATION SYSTEMS: ITS APPLICATIONS}

- Any type of application, running on any type and combination of hardware, operating system, programming language, and network can be modeled in UML.

- UML Profiles (that is, subsets of UML tailored for specific purposes) help to model Transactional, Real- time, and Fault-Tolerant systems in a natural way.

- UML is effective or modeling large, complex software systems.

- It is simple to learn for most developers, but provides advanced features for expert analysts, designers and architects.
- It can specify systems in an implementationindependent manner.

- Structural modeling specifies a skeleton that can be refined and extended with additional structure and behavior.

- Use case modeling specifies the functional requirements of system in an object-oriented manner. Existing source code can be analyzed and can be reverse-engineered into a set of UML diagrams.

- UML is currently used for applications other than drawing designs in the fields of Forward engineering, Reverse engineering, Roundtrip engineering and Model-Driven Architecture (MDA). A number of tools on the market generate Test and Verification Suites from UML models.

\section{CONCLUSION \& FUTURE SCOPE}

UML tools provide support for working with the UML language for the development of various types of information systems. From the paper, it is concluded that each UML tool is having its own functionality and can be used, according to the need of the software development cycle for the development of information systems. The three different views of using UML are: Documenting design up front, maintaining design documentation after the fact and generating refinements or source code from models. This paper has concluded with the aspect that information system can be modeled using UML due to its flexibility and inherent nature \& the tools tend to add to its ever-increasing demand for the use of development of information systems. UML can still further be considered as part of mobile development strategy and further planning can also be done to conceive the unified modeling principles for later stages of enhancement of land record information system.

Future work that could be pursued includes applying the software process to large scale m-commerce application systems and generating the model diagrams with UML, for them to be made specially tailored for the software development process; providing backbone to the analysis and design phases associated in the SDLC.

\section{REFERENCES}

[1] A. Gurd, "Using UML 2.0 to Solve Systems Engineering Problems", White Paper, Telelogic,2003.

[2] Blaha, M. \& Premerlani, W., Object-Oriented Modeling and Design for Database Applications, Prentice Hall, New Jersey,1998.

[3] R. Miller, "Practical UML TM: A Hands-On Introduction for Developers," White Paper, Object Mentor Publications,1997.

[4] B. Graham, "Developing embedded and mobile Java technology-based applications using UML," White Paper, IBM Developerworks,2003.

[5] Y. . Fowler, UML Distilled: a brief guide to the standard object modeling language, 3rd ed., Addison- Wesley,2004.

[6] P.Jalote, A.Palit, P.Kurien, V.T. Peethamber,"Timeboxing: A Process Model for Iterative Software Development," Journal of Systems and Software (JSS), Volume 70, Number 1-2, pp.117-127, 2004. 
[7] Nikolaidou M., Anagnostopoulos D., "A Systematic Approach for Configuring Web-Based Information Systems", Distributed and Parallel Database Journal, Vol 17, pp 267-290, Springer Science, 2005.

[8] M. Shaw, and D. Garlan, Software Architecture: Perspectives on an Emerging Discipline, Prentice Hall, 1996.

[9] Kobryn, C., "UML 2001: a standardization odyssey", Comm. of the ACM, Vol. 42 No. 10, October, pp. 29-37,1999.

[10] OMG UML Revision Task Force,OMG-Unified Modeling Language Specification, http://uml.systemhouse.mci.com/

[11] Jeusfeld, M.A. et al.: ConceptBase: Managing conceptual models about information systems. Handbook of Information Systems, Springer-Verlag ,pp. 265-285,1998.

[12] Berardi D., Calvanese D., and De Giacomo G.: "Reasoning on UML class diagrams", Artificial Intelligence, 168, 70-118,2005.

\section{AUthors PROFILE}

Er. Kanwalvir Singh Dhindsa is currently an Assistant Professor at CSE \& IT department of B.B.S.B.Engg.College, Fatehgarh Sahib (Punjab), India. He received his M.Tech. from Punjabi University, Patiala (Punjab) and is currently pursuing Ph.D. degree in Computer Engineering from the same university. His research interests are Information Systems, Relational Database Systems and Modelling Languages. He is a member of IEI, ISTE and ACEEE.

Prof. (Dr.) Himanshu Aggarwal is currently an Reader at department of Computer Engg. of Punjabi University,Patiala(Punjab). He received his Ph.D. degree in Computer Engineering from Punjabi University in 2007. His research interests are Information Systems, Parallel Computing and Software Engineering. He has contributed 14 papers in reputed journals and 35 papers in national and international conferences. He is also on the editorial board of some-international-journals. 